\title{
POLUIÇÃO AMBIENTAL, UM PROBLEMA DE URBANIZAÇÃO E CRESCIMENTO DESORDENADO DAS CIDADES
}

\author{
Anderson Martins Vianna \\ Graduando em Ciências Biológicas - UERJ \\ Estagiário de Iniciação Científica do OUERJ - RJ, Brasil \\ $\bowtie$ anderson.mvianna@gmail.com
}

\section{Resumo:}

O objetivo deste trabalho foi apresentar os principais tópicos sobre poluição ambiental. Poluição eletrônica (o mau descarte dos produtos eletrônicos gerando riscos para a saúde de pessoas que trabalham da reciclagem do lixo), poluição de solos, onde se explicita dois grandes fatores, os lixões clandestinos (onde são dispensados diversos tipos de resíduos, inclusive os hospitalares) e o uso de agrotóxicos, poluição do ar que explica alguns meios de poluição e quais as consequências para seres humanos, poluição de corpos hídricos que aponta os problemas dos esgotos não tratados, chorume entre outros, dando também a devida importância a outras fontes secundarias e não tão em voga quanto os tipos mencionados anteriormente. Ainda se levou em consideração a importância dos bioindicadores para a pesquisa, pois estes são de suma importância para identificação da qualidade ambiental desses meios.

Palavras-chave: Poluição; Recursos Hídricos; Bioindicadores.

\section{ENVIRONMENTAL POLLUTION, DEVELOPMENT OF A PROBLEM AND OVERCROWDED CITIES}

\begin{abstract}
:
The objective was to present the main topics on environmental pollution. Electronic pollution (bad disposal of electronic products generating risks for the health of people who work on waste recycling), pollution of soil, where it spells out two major factors, illegal dumps (where various types of waste are exempt, including hospital ) and the use of pesticides, air pollution which explains some pollution means and what the consequences for humans, pollution of water bodies that points out the problems of untreated sewage, manure among others, also giving due importance to other secondary sources and not as in vogue as the types mentioned above. Still it considered the importance of biomarkers for research, which are of paramount importance to identify the environmental quality of these means.
\end{abstract}

Keywords: Pollution; Water Resources; Bioindicators. 


\title{
CONTAMINACIÓN AMBIENTAL, DESARROLLO DE UN PROBLEMA Y CIUDADES SUPERPOBLADAS
}

\begin{abstract}
Resumen
El objetivo fue presentar los temas principales de la contaminación del medio ambiente. Contaminación Electrónico (mala disposición de los productos que generan riesgos electrónicos para la salud de las personas que trabajan en el reciclaje de residuos), contaminación del suelo, donde se explica en detalle dos factores principales, vertederos ilegales (donde diferentes tipos de residuos están exentos, incluyendo el hospital) y la uso de pesticidas, la contaminación del aire que explica algunos medios de contaminación y cuáles son las consecuencias para los seres humanos, la contaminación de los cuerpos de agua que señala los problemas de aguas residuales no tratadas, estiércol, entre otros, también se da la debida importancia a otras fuentes secundarias y no como en boga como la tipos mencionados anteriormente. Aún así, considera la importancia de los biomarcadores para la investigación, que son de vital importancia para identificar la calidad ambiental de estos medios.
\end{abstract}

Palabras clave: Contaminación; Recursos Hídricos; Bioindicadores.

\section{INTRODUÇÃO}

A segunda metade do século XX foi marcada por uma ampla discussão da questão ambiental. Em 1972, com a publicação do relatório "Os Limites do Crescimento", o mundo foi apresentado as possíveis consequências da forma a qual o meio ambiente era explorado, destacando os cinco fatores determinantes e/ou limitadores do crescimento: população, produção agrícola, recursos naturais, produção industrial e poluição (OLIVEIRA, 2009). O impacto ambiental das nações após a Revolução Industrial se mostrou um risco ao futuro da humanidade, e sucessivos movimentos internacionais surgiram para formalizar um compromisso internacional com a problemática ambiental. Dentre esses destacam-se: a Conferência de Estocolmo, em 1972, onde foi criado o Programa das Nações Unidas para o Meio Ambiente (PNUMA); a publicação do relatório "Nosso Futuro Comum" (Our Common Future) pela Comissão Brundtland, pertencente à ONU; e a Eco 92, ou Rio 92, onde foi aprovada a "Agenda 21"(LIMA, 1999; OLIVEIRA, 2009). Dentre diversos tópicos, a Poluição Ambiental sempre foi foco, seja para prevenção, monitoramento e/ou remediação.

A discussão do tema Poluição Ambiental, leva ao encontro da necessidade de entender o conceito de poluição. Como a área ambiental é uma interface multidisciplinar, este que pode ser apresentado de diversas maneiras, de acordo com o olhar jurídico ou ambiental, ou ainda por definições de outros setores.

Considera-se poluição "toda e qualquer alteração das propriedades naturais do meio 
ambiente que seja prejudicial à saúde, à segurança ou ao bem-estar da população sujeita aos seus efeitos, causada por agente de qualquer espécie” (MANO et al., 2005). Esta é uma definição didática, de origem acadêmica. Porém em outros campos onde se faz necessária um maior pragmatismo semântico, como no empresarial, se faz necessária sua própria definição sobre poluição ambiental:

"Poluição ambiental pode ser definida como toda ação ou omissão do homem que, pela descarga de material ou energia atuando sobre as águas, o solo, o ar, causa um desequilíbrio nocivo, seja ele de curto, seja de longo prazo, sobre o meio ambiente. A definição do agente causador de poluição é dada como ser uma pessoa física ou jurídica de direito público ou privado, responsável direta ou indiretamente pela atividade causadora da degradação ambiental." (VALLE, 2004, p.49).

Porém até na mesma área de atuação, como a legislativa, o conceito pode variar, caracterizando uma dificuldade para a definição deste conceito. Cerri Neto e Ferreira (2009) denunciam essas diferenças do conceito de poluição até mesmo entre as leis federais e estaduais, como pode ser observado no Quadro 1.

Quadro 1 - Conceitos de poluição extraídos de referências legais

\begin{tabular}{|c|c|}
\hline Referência & Conceito \\
\hline $\begin{array}{l}\text { BRASIL, LEI FEDERAL } n^{*} 6.938 \text {, de } 31 \text { de } \\
\text { agosto de } 1981 \text {, Politica Nacional do Meio } \\
\text { Ambiente. Art. } 3^{\circ} \text {, III. }\end{array}$ & $\begin{array}{l}\text { Poluição } \\
\text { A degradaçăo da qualidade ambiental resultante de atividades que direta ou } \\
\text { indiretamente: } \\
\text { a) prejudiquem a saúde, a segurança e o bem-estar da populaçăo; } \\
\text { b) criem condiçōes adversas às atividades sociais e econômicas; } \\
\text { c) afetem desfavoravelmente a biota; } \\
\text { d) afetem as condiçōes estéticas ou sanitárias do meio ambiente; } \\
\text { e) lancem matérias ou energia em desacordo com os padrōes ambientais estabelecidos. }\end{array}$ \\
\hline $\begin{array}{l}\text { SĀO PAULO. LEI ESTADUAL n`9.509, de } \\
20 \text { de março de } 1997 \text {, Politica Estadual do } \\
\text { Meio Ambiente. Art. } 3^{\circ} \text {, III. }\end{array}$ & $\begin{array}{l}\text { Poluição } \\
\text { A degradação da qualidade ambiental resultante de atividades que direta ou } \\
\text { indiretamente: } \\
\text { a) prejudiquem a saúde, a segurança e o bem-estar da população; } \\
\text { b) criem condiçōes adversas às atividades sociais e econômicas; } \\
\text { c) afetem desfavoravelmente a biota; } \\
\text { d) afetem as condiçōes estéticas ou sanitárias do meio ambiente; } \\
\text { e) lancem matérias ou energia em desacordo com os padrōes ambientais estabelecidos; } \\
\text { f) afetem desfavoravelmente a qualidade de vida. }\end{array}$ \\
\hline $\begin{array}{l}\text { SĀO PAULO, LEI ESTADUAL } n^{\circ} 997 \text {, de } \\
31 \text { de maio de } 1976, \text { Art. } 2^{\circ} \text {. }\end{array}$ & $\begin{array}{l}\text { Poluição } \\
\text { A presença, o lançamento ou a liberação, nas águas, no ar ou no solo, de toda e } \\
\text { qualquer forma de matéria ou energia, com intensidade, em quantidade, de } \\
\text { concentraçăo ou com caracteristicas em desacordo com as que forem estabelecidas em } \\
\text { decorrência desta Lei, ou que tornem ou possam tornar as águas, o ar ou o solo: } \\
\text { I-impróprios, nocivos ou ofensivos à saúde; } \\
\text { II - inconvenientes ao bem estar público; } \\
\text { III - danosos aos materiais, à fauna e à flora; } \\
\text { IV - prejudiciais à segurança, ao uso e gozo da propriedade e às atividades normais da } \\
\text { comunidade. }\end{array}$ \\
\hline
\end{tabular}

Fonte: CERRI NETO e FERREIRA, 2009. 
Quanto à classificação de Poluição Ambiental, esta pode ser: hídrica, do solo, da atmosfera, entre outras. Quanto à natureza dos agentes poluidores, esses ambientes podem ser contaminados por compostos químicos, esgotos, resíduos eletrônicos e orgânicos.

Estes resíduos eletrônicos e/ou orgânicos, lixo, são continuamente dispersados no meio ambiente. $\mathrm{O}$ descaso com esse fato, seja por serem material de pequeno porte, por não receberem uma campanha de conscientização mais intensa ou até mesmo punições mais rigorosas, constitui um grave problema ambiental (RIBEIRO e BESEN, 2008).

Apesar disso, a relevância do problema da poluição motivou sua abordagem, numa perspectiva educacional, a ser trabalhada na Educação Básica. Dado compromisso foi firmado através dos Parâmetros Nacionais Curriculares (PCN) - Meio Ambiente (BRASIL, 1998). Este documento constituiu-se numa tentativa do MEC em propor uma mudança curricular e metodológicas nas práticas educacionais presentes na escola. Para os diferentes sistemas que compõem a estrutura educacional brasileira, os PCN se apresentam como um referencial. (PALMA FILHO, 1997; RICARDO e ZYLBERSZTAJN, 2007).

A temática da poluição vem sendo muito mais frequentemente abordada visto que, as questões ambientais vêm tomando grande importância para o futuro da sociedade, sendo, portanto incluída neste documento educacional brasileiro. Há uma necessidade de compreensão e conscientização a respeito da preservação do planeta, já que a manutenção da vida e dos recursos naturais provem dele, e que a qualidade de vida está diretamente relacionada ao nível de poluição e degradação ambiental (BRASIL, 1998).

A intensidade do consumo pode ser um grande problema. Celulares, dentre diversos outros aparelhos eletroeletrônicos, embora de extrema utilidade no cotidiano, são trocados frequentemente por conta de defeitos, ou novas demandas oriundas da constante evolução tecnológica (KASPER et al., 2009 ). O ponto mais preocupante não é essa troca, e sim o descarte do aparelho antigo, mais especificamente, suas baterias. Estas são jogadas em rios, terrenos baldios ou lixeira comum. Uma vez descartada desta forma, será tratada como um resíduo comum, recebendo um tratamento ineficaz, já que esta possui substâncias tóxicas prejudiciais para saúde ambiental e do ser humano. A manipulação inadequada das diversas substâncias presentes nas baterias de celular podem gerar diversas doenças, como estomatite, disfunção renal, e até mesmo problemas neurológicos e pulmonares além das queimaduras na pele e nos olhos (KASPER et al., 2009 ; FURTADO, 2004). 
O crescimento urbano é acompanhado aumento da poluição ambiental. $O$ desenvolvimento das cidades gera cada vez mais lixo, principalmente resíduos que levam muito tempo para ser degradado pelo meio ambiente. Consequentemente esse lixo se deposita em lugares indevidos, como rios, solos desprotegidos, afetando tanto a fauna quanto a flora. As cidades também por crescerem de forma muito acelerada e desorganizada possuem grandes congestionamentos de veículos, com isso gerando também poluição do ar, o que nos leva ainda a repensar as questões energéticas ligadas a utilização de combustíveis (SILVA et al., 2014).

Segundo a CETESB (2015) são consideradas poluentes do ar quaisquer substancias que possam gerar qualquer consequência nociva e tornar o ar impróprio. A poluição do ar também pode ser prejudicial para outros elementos bióticos como plantas e animais. Em seres humanos podem não só gerar, mas também agravar diversos problemas respiratórios e cardiovasculares (GOUVEIA et al., 2003).

No decorrer deste artigo serão apresentados diversos tipos de poluição, suas formas de geração e algumas maneiras para diminuir a sua agressão ao meio ambiente.

\section{Poluição Eletrônica}

Poluição eletrônica ocorre pelo acúmulo de materiais eletrônicos, oriundos do descarte constante e mau armazenamento em um local sem nenhum tratamento prévio. Este tipo de poluição vem crescendo em virtude do alto consumo deste tipo de produto, muitas vezes aliado a facilidades econômicas de aquisição. O descarte excessivo é resultado de inovações tecnológicas cada vez mais aceleradas de modo a atender as mais diversas atividades do cotidiano (FERREIRA e FERREIRA, 2008).

Há um tempo, não existia a preocupação com esses resíduos eletrônicos, sendo assim estes eram tratados como o nosso lixo comum, pois não se tinha ideia do prejuízo que estes poderiam trazer. A destinação inadequada destes resíduos começa pelo fato dos consumidores não estarem bem instruídos pelos fabricantes sobre o perigo do descarte de baterias no meio ambiente, bem como pela escassez de investimentos em campanhas de coleta seletiva e na disponibilização de mais lixeiras próprias para o descarte de pilhas e baterias, bem como de áreas adequadas para seu destino final (RIBEIRO e BESEN, 2008). 
"Destinação ambientalmente adequada: destinação que minimiza os riscos ao meio ambiente e adota procedimentos técnicos de coleta, recebimento, reutilização, reciclagem, tratamento ou disposição final de acordo com a legislação ambiental vigente." (CONAMA, Resolução n 401/2008, cap. I, art. $2^{\circ}$, inciso IX )

As pilhas e baterias não representam todos os resíduos eletrônicos, sendo estes apenas uma pequena parte deste problema. Os computadores também contribuem para este tipo de poluição devido ao mesmo fato de constante avanço tecnológico e a necessidade que o ser humano tem possuí-las. Com isso, gera a troca de peças por novas, consequentemente há aumento da quantidade de lixo eletrônico. Muitas pessoas imaginam que esses rejeitos eletrônicos são apenas metal e plástico. Os metais utilizados em sua confecção são fatores tóxicos e frequentemente contaminantes do solo. Estas ligas metálicas possuem na sua composição cádmio, mercúrio e arsênio que podem causar problemas nos ossos, danos no cérebro e câncer no pulmão respectivamente (KASPER et al., 2009). A tabela 1 mostra onde estes resíduos podem ser encontrados e os malefícios que estes podem causar ao ser humano.

De acordo com Ferreira e Ferreira (2008) uma placa eletrônica no período de degradação gera 22mg/litro de cádmio (Cd) e $133 \mathrm{mg} /$ litro de chumbo $(\mathrm{Pb})$, enquanto que o homem suporta respectivamente, $0,5 \mathrm{mg} /$ litro e $5 \mathrm{mg} / \mathrm{litro}$ desses elementos. Nos dias de hoje, 90\% desses materiais pode ser recicláveis, deles podem ser tiradas peças que serão de utilidade até mesmo para se montar um novo aparelho, sendo que algumas empresas já oferecem esses serviços (FERREIRA e FERREIRA, 2008).

Além das sucatas serem tão prejudiciais para meio ambiente, pois contaminam o solo também ser podem ser tóxicas ao o ser humano, partindo do princípio em que tudo pode ser degradado pelo meio ambiente principalmente pela ação do tempo, um ponto desfavorável é que estes materiais levam muito tempo, as pilhas, por exemplo, podem levar de 100 a 500 anos para se degradar por completas e com isso essas pilhas ficam por todo esse tempo poluído e contaminando solos e seres humanos que vivem do lixão para sobreviver. 
Tabela 1 - Diversas substancias tóxicas e seus efeitos biológicos.

\begin{tabular}{|c|c|c|}
\hline $\begin{array}{l}\text { SUBSTÂNCIA } \\
\text { TÓXICA }\end{array}$ & $\begin{array}{l}\text { RESÍDUO ELETRÔNICO/USO } \\
\text { CONTAMINANTE }\end{array}$ & MALEFÍCIO À SAÚDE \\
\hline Mercúrio & $\begin{array}{l}\text { Computador, monitor e TV de tela } \\
\text { plana. }\end{array}$ & Danos no cérebro e fígado \\
\hline Cádmio & $\begin{array}{l}\text { Computador, monitores de tubo e } \\
\text { baterias de laptops. }\end{array}$ & $\begin{array}{l}\text { Envenenamento, problemas nos ossos, } \\
\text { rins e pulmões. }\end{array}$ \\
\hline Arsênio & Celulares & $\begin{array}{l}\text { Pode causar câncer no pulmão, doenças } \\
\text { de pele e prejudicar o sistema nervoso. }\end{array}$ \\
\hline Berílio & Computadores e celulares. & Causa câncer no pulmão. \\
\hline $\begin{array}{l}\text { Retardantes de } \\
\text { Chamas (BRT) }\end{array}$ & $\begin{array}{l}\text { Usado para prevenir incêndios em } \\
\text { diversos eletrônicos. }\end{array}$ & $\begin{array}{c}\text { Problemas hormonais, no sistema nervoso } \\
\text { e reprodutivo. }\end{array}$ \\
\hline Chumbo & Computador, celular e televisão. & $\begin{array}{c}\text { Causa danos ao sistema nervoso e } \\
\text { sanguíneo. }\end{array}$ \\
\hline Bário & Lâmpadas fluorescentes e tubos & $\begin{array}{l}\text { Edema cerebral, fraqueza muscular, } \\
\text { danos ao coração, fígado e baço. }\end{array}$ \\
\hline PVC & Usado em fios para isolar corrente & $\begin{array}{l}\text { Se inalado, pode causar problemas } \\
\text { respiratórios. }\end{array}$ \\
\hline
\end{tabular}

Fonte: http://www.ca.ufsc.br/qmc/aulas1anos/lixo/lixo.htm

\section{Poluição de Solos}

O solo além de ser um recurso ambiental renovável também participa essencialmente da Humanidade através da agricultura e pecuária através dos tempos. Embora o solo seja tão importante sua preservação nem sempre é observada, gerando os fenômenos de erosão e voçoroca que consomem e destroem o solo, impossibilitando as diversas atividades, bem como a própria manutenção humana. Diversos resíduos por suas características químicas podem contaminar o solo e o lençol freático, dispersando assim a poluição a grandes distâncias.

A presença de materiais poluentes em lixões (que embora proibidos, ainda existem em nossas cidades) permite a exposição de "catadores de lixo" que nestas áreas retiram o seu 
sustento e podem adquirir diversas enfermidades de cunho infecto parasitário, mas também ambiental por contaminação pelos diversos materiais químicos aos quais se expõem durante sua atividade. Esse fato é agravado quando encontramos lixo orgânico misturado com materiais hospitalares que além de veicular doença, podem causar acidentes por perfurocortantes (CAVALCANTE e FRANCO, 2007).

Lixões clandestinos também geram problemas para o meio ambiente e principalmente para o solo devido à produção do chorume, onde este é definido como resíduo líquido de elevada carga orgânica e forte coloração, produzido pela decomposição química e microbiológica dos resíduos sólidos depositados em um aterro. A atividade contaminante do chorume pode alcançar e contaminar aquíferos (NOBREGA et al., 2009).

O tratamento correto do chorume é a impermeabilização do solo com uma manta de polietileno de alta densidade (PEAD), criar valas por onde este poderia escorrer e mantendo-o armazenado em lagoas de tratamento. $\mathrm{O}$ tratamento pode ser biológico como lagoas anaeróbias e de estabilização, tratamento por oxidação que seria a queima e evaporação ou ainda poderia ser realizado um tratamento químico com adição de substâncias ao chorume. Estes procedimentos são típicos de um aterro sanitário. A principal providência a ser tomada seria a melhor fiscalização aliada a multas mais rígidas contra os fundadores dos lixões clandestinos ou empresários que contratam esses serviços para não ter que custear uma empresa especializada no tratamento e no descarte do seu lixo.A inobservância destes métodosacaba por descartar os resíduos em qualquer ambiente colocando em risco a saúde das pessoas que moram próximos a estes lixões ou em locais de proteção ambiental causando danos diretos ao meio ambiente (CESTESB, 2015; NOBREGA et al;; 2009; DANTAS e FERREIRA JUNIOR, 2012).

Outra prática importante para a sociedade é a agricultura, mas esta também gera resíduos que poluem o solo podendo inutilizá-lo, ou seja, torna-lo impróprio para o plantio (BARREIRA e PHILIPPI JUNIOR, 2002).

Os agrotóxicos são utilizados para proteger o plantio contra pragas, mas são muito inespecíficos e acabam por prejudicá-lo indiretamente,pois prejudicamo solo diretamente, e ainda possuem substâncias que podem alterar o $\mathrm{pH}$ do solo ou alterara solubilidade de algumas substâncias no mesmo (ALVES e OLIVEIRA-SILVA, 2003). 
Segundo a atual legislação, compete ao Ministério da Agricultura, Pecuária e Abastecimento realizar a variação de eficácia agronômica, ao Ministério da Saúde de executar a avaliação e classificação Toxicológica e ao Ministério do Meio Ambiente avaliar e classificar o potencial de periculosidade ambiental. Já que os impactos gerados pelo uso destas substâncias variam de acordo com as propriedades físico-químicas dos produtos, bem como seu modo de aplicação. O tipo de ambiente com o qual o agrotóxico interage também é determinante para a mensuração da magnitude e gravidade de seu impacto na saúde humana e ambiental (RIBEIRO e CAMELLO, 2014).

Existem várias maneiras de contaminação do solo por agrotóxicos. A contaminação direta é quando existe um vazamento, derramamento ou lançamento direto no solo. Indiretamente ocorre pelo vento, lavagem das plantas por irrigação, pela água da chuva ou pela incorporação dos restos de biomassa dessas plantas no solo e ainda pela transferência da mesma para o solo, absorvendo e transferindo essas substâncias (BARREIRA e PHILIPPI JUNIOR, 2002).

Segundo Correia et al., 2007, a adsorção, responsável pela ligação dos agrotóxicos ao solo, influencia os processos de transporte por lixiviação, escorrimento superficial e volatilização. Mostrando- se um grande problema, pois estes podem poluir tanto o ar quanto o solo e corpos d'água.

\section{Poluição do Ar}

São considerados poluentes qualquer substancia que possa ser nociva ou impropria a saúde, devido a sua concentração, ou até mesmo ser inconveniente ao público ou a fauna e a flora ou ainda mesmo afetar diretamente a segurança (CETESB, 2015).

O ser humano inspira 10 mil litros de ar por dia consumindo 400 litros de oxigênio em médiae este ar não possui qualquer tipo de tratamento diferente da água que recebe um tratamento prévio até chegar às casas, logo há a necessidade do monitoramento da qualidade do ar (SOARES, 2004; CETESB, 2015).

Comparando os modos de vida da cidade com a zona rural, notamos que as cidades possuem uma maior concentração de poluentes do ar devido à contribuição de poluentes produzidos por indústrias, grande fluxo de automóveis se locomovendo pela cidade 
constantemente e pelas construções de novos empreendimentos que também contribuem demasiadamente para a poluição do ar (CARVALHO et al., 2013).

Embora hoje em dia existam todos esses fatores mencionados anteriormente na zona rural, ainda assim estão em menor proporção em comparação com a cidade (CARVALHO et al., 2013), um fator positivo para essas áreas são a presença de grandes áreas verdes que contribuem para diminuir da poluição do ar, mas atualmente muitas indústrias são levadas para lugares afastados dos grandes centros para evitar conflitos socioambientais,porque pessoas que vivem próximas a essas indústrias ficam mais suscetíveis a problemas respiratórios, com isso gerando problemas judiciais contra essas indústrias (GOUVEIA et al., 2003).

Atualmente devido à suscetibilidade de algumas pessoas a doenças respiratórias, passou-se a ter uma maior preocupação com a qualidade do ar. Sabe-se que o Brasil sediou a copa do mundo de 2014 e a FIFA exigiu o monitoramento do ar nas cidades cede da copa do mundo, onde Rio de janeiro, São Paulo e Rio Grande do Sul (este possui relatórios diários) dando destaque para esta última, que já possuía na época um maior número de estações de monitoramento (FIFA, 2011; VORMITTAG et al., 2014)

\section{Poluição de Corpos Hídricos}

Poluição hídrica é qualquer alteração que indireta ou diretamente devido a adição de substância ou energia que altere as propriedades químicas e físicas da água inviabilizando a exploração dos seus benefícios (PRODANOFF, 2005).

A água é considerada um dos bens naturais mais valiosos que existem, porque grande parte da água que temos disponíveis no mundo é salgada, mas para nosso consumo direto necessitamos de água doce, onde está representa uma pequena parte do total de água existente no planeta, logo se deve cuidar dessa pequena parte tão essencial para a existência dos seres vivos, mas isso não acontece, devido à ambição do ser humano, este não se preocupa com as consequências, esquecendo-se da importância desse bem (RODRIGUES e MOLINA, 2012).

Além disso, a água potável do planeta está em grande escassez e esta é essencial para a existência da vida humana entre outros animais, uma vez que os seres humanos que não conseguem sobreviver mais de três dias sem água. Devem-se então preservar todos os corpos 
hídricos, uma vez que os mares são uma grande fonte de alimentos e também detentor de um ecossistema colossal, caso não ocorra esta preservação pode-se ocorrer a extinção de milhares de espécies e assim causar danos irreparáveis a este ecossistema. Os corpos hídricos são diariamente contaminados por indústrias, descartes de produtos e entre outros (NASCIMENTO e HELLER, 2005).

Um dos maiores problemas é o esgoto que em alguns lugares são despejados nos rios e mares sem nenhum tratamento prévio, com isso contaminando os corpos hídricos potáveis e os esgotando. Os esgotos domésticos contribuem para o aumento da matéria orgânica e consequentemente ocorre uma proliferação de algas e a diminuição de oxigênio na água causando a mortandade de peixes (NASCIMENTO e HELLER, 2005; BRUNO, 2006).

Esgotos e o lixo jogado nos rios trazem doenças e podem favorecer enchentes. Se os próprios moradores estiverem conscientes dos malefícios que isso pode trazer principalmente para eles próprios, estarão preparados para contribuir com a limpeza urbana e assim diminuir os riscos da poluição.

Outro fator que contribui para a poluição de corpos hídricos é o uso demasiado de pesticidas, onde estes em sua maioria são tóxicos, podendo ter atividade mutagênica, carcinogênica, teratogênica e mimetizadoras de hormônios. Além desses pesticidas serem utilizados em grandes regiões, o que consequentemente aumenta a área de poluição, o problema está na forma de dispersão desse pesticida que é feito por irrigação ou são borrifados manualmente e depois este escoa pelo solo podendo chegar até corpos hídricos superficiais ou mesmo subterrâneos, como lençóis freáticos (BARREIRA e PHILIPPI JUNIOR, 2002).

Existem outras formar de poluir os corpos hídricos, e a tabela seguinte (Tabela 1) mostra quem são os poluidores, e a intensidade na zona rural ou urbana e seus efeitos. 
Tabela 1: Principais Agentes Poluidores das Águas.

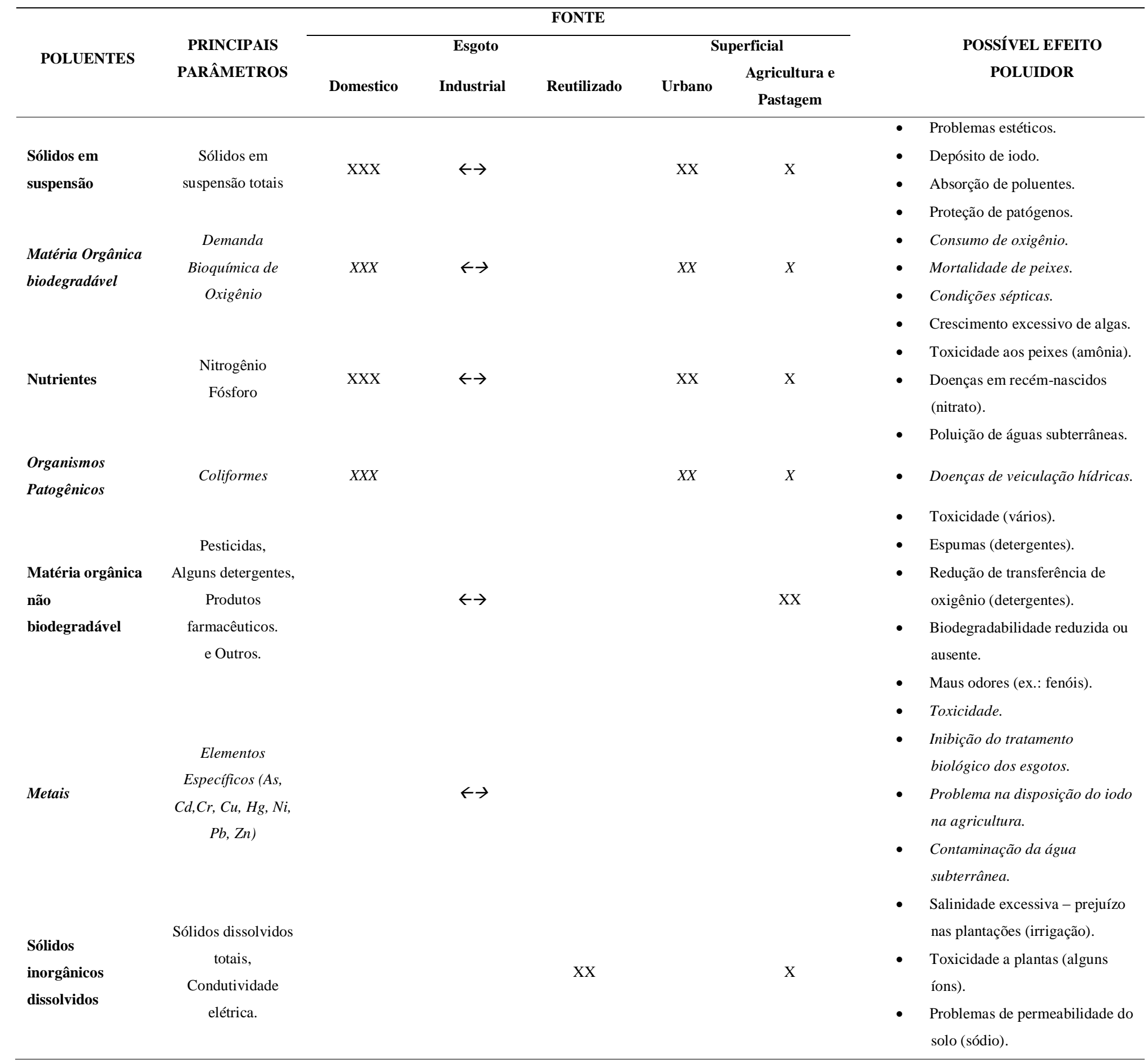

Legenda: XXX - Muito; XX - Médio; X - Pouco; $\leftarrow \rightarrow$ - Variável; Em branco - usualmente não importante. 


\section{Efluentes e fertilizantes}

Os defensivos agrícolas ou fertilizantes afetam muito os corpos hídricos contaminando lençóis freáticos rios, lagos e solos, essa contaminação pode ser por despejo do resto da solução, limpeza dos recipientes ou dos acessórios utilizados em sua aplicação. O grande problema enfrentado com os fertilizantes é a destinação de suas embalagens que é considerada como resíduo perigoso pois esses possuem substancias químicas que podem comprometer as formar de vidas no ambiente além de ser prejudicial a saúde da população principalmente pelo desperdício nas aplicações levando a contaminação dos alimentos (BARREIRA e PHILIPPI JUNIOR, 2002).

Na mesma vertente estão os efluentes que são definidos pela Resolução CONAMA n ${ }^{\circ}$ 430/2011(CONAMA, 2011) como "qualquer despejo líquido proveniente de diversas atividades ou processos". Estes efluentes são principalmente gerados por indústrias. Mas para que sejam considerados efluentes contaminantes precisam conter compostos químicos ou espécies biológicas com a capacidade inviabilizar o consumo do corpo hídrico receptor, seja pela decomposição de matérias orgânicas que geram o consumo o consumo de oxigênio afetando a vida aquática e gerando condições desagradáveis.

\section{Chuva Ácida}

Em áreas com a presença de industrias existem muitos gases tóxicos como monóxido de carbono e dióxido de enxofre e muito material particulado contribuído para poluição do ar, mas esses poluentes também são responsáveis pala formação da chuva ácida que se dá pela queima de combustíveis fósseis libera compostos que interagem com as moléculas de $\mathrm{H}_{2} \mathrm{O}$ presentes no ar, podendo formar os ácidos nítrico e sulfúrico com isso deixando a água da chuva mais ácida e gerando impactos ao meio ambiente como por exemplo corroendo arvores poluindo lagos e atingindo também fauna e até mesmo a produção energética pois a acidez da água pode corroer o concreto dos reservatórios, bombas e turbinas. A chuva ácida também impacta os solos lixiviando os nutrientes e eliminando organismos que contribuem para o equilíbrio do mesmo (BRAGA et al., 2005 e SILVA et al., 2014).

\section{Indústria Petrolífera}

As indústrias petrolíferas possuem também um alto potencial poluidor desde a perfuração dos poços até o transporte. O transporte é de fato a etapa mais perigosa, pois 
podem ocasionar grandes derramamentos de óleo dos navios petroleiros ocasionando impactos ao ecossistema como diminuição do $\mathrm{pH}$, do oxigênio dissolvido e alimentos disponíveis, este irá diminuir devido a diminuição da taxa fotossintética pois óleo ira cobrir toda superfície da água impedindo a entrado de oxigênio e a luz do sol (BRUNO, 2006).

\section{Poluição Térmica}

A alteração da temperatura também pode alterar as propriedades físicas biológicas e químicas da água sendo assim também sendo caracterizada como poluição podendo a solubilidade de gases, tensão superficial, metabolismo de organismos aquáticos e até mesmo causar migrações de peixes para regiões com maior concentração de oxigênio. $\mathrm{O}$ aquecimento dos efluentes é decorrente principalmente das atividades das usinas termoelétricas independente do combustível fóssil (BRAGA et al.,2005).

\section{Fontes difusas}

A poluição hídrica pode acontecer de forma pontual ou difusa, onde a pontual é uma alteração local, como exemplo podemos citar um duto coletor de esgoto não tratado desembocando em um corpo hídrico. Já poluição difusa acontece devido a lavagem da chuva sobre o solo rural ou urbano carreando diversos tipos de poluição para rios lagos e baias. A poluição difusa pode ter diversas origens como, resíduos orgânicos de animais resíduos de construção civil, combustíveis, graxas e óleos originados pelos veículos estes também desgastam o asfalto gerando mais resíduos, não podendo deixar de mencionar os resíduos orgânicos, (restos de alimentos) metais como zinco, cobre, chumbo e os poluentes do ar que se depositam sobre o solo (ELLIS, 1986 ; PRODANOFF, 2005).

\section{Bioindicadores}

Bioindicadores são espécies, grupos de espécies ou comunidades biológicas cuja presença, abundância e condições são indicativos biológicos de uma determinada condição ambiental. Os bioindicadores são importantes para correlacionar com um determinado fator antrópico ou um fator natural com potencial impactante, representando uma importante ferramenta na avaliação da integridade ecológica (condição de "saúde" de uma área, definida pela comparação da estrutura e função de uma comunidade biológica entre uma área impactada e áreas de referência) (ICB-UFMG, 2015). 
Os bioindicadores possuem funções mais especificas e podem ser usados como ferramentas em diversos contextos como, mudanças climáticas, indicador de sucessão ecológica, degradação de solos, contaminação e até mesmo a destruição do ambiente. Para que o desenvolvimento dessas funções seja bem executado os bioindicadores necessitam de estudo prévio da biologia dos organismos utilizados, consequentemente estes devem ser sensíveis as alterações avaliadas, logo os bioindicadores são ferramentas muito utilizadas no monitoramento de áreas degradas, por fornecerem indicativos em relação ao progresso florestal (WINK et al., 2005).

Estes bioindicadores são muito importantes para se checar as condições de saúde desses ambientes apresentados anteriormente neste estudo, sendo que para cada um desses ambientes existe seu grupo especifico de organismos.

Um bioindicador muito utilizado para verificar a qualidade do ar são os liquens, pois estes se alimentam higroscopicamente, fixando elementos principalmente o nitrogênio, mas também absorvem os elementos radioativos (GONÇALVES et al., 2007).

No caso dos solos um bom bioindicador para agrotóxicos e fertilizantes de uso agrícola, resíduos de atividades industriais, petróleo e metais entre outros, são as minhocas. Estes invertebrados, além de ter toda uma importância para saúde do solo, aerando-o, é a maior biomassa presente no mesmo. Elas podem através do contato direto com a cutícula absorver os contaminantes do solo. Estes organismos podem ser intoxicados até a morte, ou ainda bioacumularem estas substâncias em seus tecidos e sobreviverem. São chamados de bioindicadores-sentinela, pois o acúmulo de contaminantes em seus tecidos fornecem informações importantes como biodisponibilidade dos poluentes e o padrão de contaminação (ANDRÉA, 2010).

Para medir a qualidade da água igualmente podemos utilizar bioindicadores que também se mostram muito eficientes para essa medição, são os macroinvertebrados aquáticos, pois estes são abundantes, possuem um baixo custo e uma grande longevidade e possuem uma relação com o enriquecimento orgânico dos corpos hídricos e uma baixa motilidade, a ausência ou mortandade de algumas espécies típicas desse ambiente pode caracterizar algum problema na qualidade da água (SILVA, et al., 2009). 


\section{CONCLUSÃO}

Os diversos tipos de poluição de maneira direta ou indireta acompanham a atividade antropogênica, e podem prejudicar a vida humana de diversas maneiras e intensidades. A preocupação com a diminuição da qualidade ambiental por conta dos diversos tipos de poluição vem trazendo reflexões à sociedade que então une forças para encontrar soluções.

Uma das soluções para melhorar a qualidade de vida é a aplicação de tecnologias, maiores investimentos em obras públicas e conhecimento científico.

O investimento em reciclagem deve acompanhar os esforços de produção, de modo a gerar menos resíduos e menor poluição. Porém isso não é o suficiente, se faz necessário ter também uma melhor fiscalização do destino final dos resíduos, aplicação de multas e principalmente uma melhor abordagem educativa.

A conscientização e o monitoramento são fatores importantes, pois os maiores prejudicados neste contexto são os próprios seres humanos. A queda na qualidade de vida, a escassez de água potável, a diminuição dos alimentos e aumento nos poluentes do ar, comprometem a vida humana. A “engrenagem” desta "máquina” chamada Terra, é intrincada e depende do compromisso do ser humano em entender o seu poder de influência na Terra e responsabilidade com os outros seres vivos da Terra. 


\section{REFERENCIAS CONSULTADAS}

ALVES, S. R.; OLIVEIRA-SILVA, J. J.. Avaliação dos Ambientes Contaminados por Agrotóxicos. In: PERES, F.; MOREIRA, J. C. (Org.). É veneno ou é remédio?: agrotóxicos, saúde e ambiente. Rio de Janeiro: Editora Fiocruz, 2003. Cap. 7. p. 137-156. Disponível em: $<$ https://portal.fiocruz.br/sites/portal.fiocruz.br/files/documentos/cap_07_veneno_ou_remedio .pdf>. Acesso em: 28 maio 2015.

ANDRÉA, M. M.. O uso de minhocas como bioindicadores de contaminaçao de solos. Acta Zoológica Mexicana, Xalapa, v. 26, n. 2, p.95-107, jan. 2010. Número Especial. Disponível em: $\quad\langle$ http://www.scielo.org.mx/scielo.php?script=sci_arttext\&pid=S006517372010000500007\&lng=es\&nrm=iso >. Acesso em: 28 maio 2015.

BARREIRA, L. P.; PHILIPPI-JUNIOR, A.. A problemática dos resíduos de embalagens de agrotóxicos no Brasil. In: APAGAR, 28., 2002, Cancún, México. XXVIII Congreso Interamericano de Ingeniería Sanitaria y Ambiental. Cancún: Aidis, 2002. Disponível em: <http://www.bvsde.paho.org/bvsaidis/mexico26/iv-001.pdf $>$. Acesso em: 28 maio 2015.

BRAGA, B., HESPANHOL, I., CONEJO, J. G. L., MIERZWA, J. C., BARROS, M. T., SPENCER, M.; PORTO, M.; NUCCI, N.; JULIANO, N.; EIGER, S.. Introdução à Engenharia Ambiental: o Desafio do Desenvolvimento Sustentável. 2. ed. São Paulo: Pearson Prentice Hall, 2005. 318 p.

BRASIL. Parâmetros Curriculares Nacionais: Meio Ambiente. Brasília: Ministério da Educação (MEC), $1998 . \quad 76 \quad$ p. $\quad$ Disponível em: $\langle$ http://portal.mec.gov.br/seb/arquivos/pdf/meioambiente.pdf $>$. Acesso em: 28 maio 2015.

BRASIL. Parâmetros Curriculares Nacionais: Saúde. Brasília: Ministério da Educação (MEC), 1998. 31 p. Disponível em: 〈http://portal.mec.gov.br/seb/arquivos/pdf/livro092.pdf〉. Acesso em: 28 maio 2015.

BRUNO, A. P. V.. Poluição por Petróleo nos Ambientes Marinho e Costeiro. 2006. 29 f. Monografia (Especialização) - Curso de Especialização em Ciências Biológicas, UNISUAM, Rio de Janeiro, 2006.

CARVALHO, R. R.; MACIEL, K. L. de S.; DE OLIVEIRA, M. R. A.; GOMES, R. C.; FREITAS, T. C.; LEITE, J. R..Meio ambiente e qualidade de vida: um estudo comparativo nos ambientes rural e urbano do município de Codó-MA. In: $64^{\mathrm{a}}$ REUNIÃO ANUAL DA SBPC, 64., 2013, São Luís. Educação Ambiental. São Luís: SBPC, 2013. Disponível em: <http://www.sbpcnet.org.br/livro/64ra/resumos/resumos/9021.htm>. Acesso em: 28 maio 2015 .

CAVALCANTE, S.; FRANCO, M. F. A.. Profissão perigo: percepção de risco à saúde entre os catadores do Lixão do Jangurussu. Revista Subjetividade, Fortaleza, v. 7, n. 1, p.211-231, mar. 2007. Disponível em: 〈http://ojs.unifor.br/index.php/rmes/article/view/1581〉. Acesso em: 28 maio 2015.

CERRI NETO, M.; FERREIRA, G. C.. Poluição: Incompatibilidades entre conceitos legal e técnico. Revista Geociências,São Paulo, v. 28, n. 2, p.165-180, 2009. Disponível em: 
<http://www.periodicos.rc.biblioteca.unesp.br/index.php/geociencias/article/view/3506>. Acesso em: 23 maio 2015.

CETESB. Aterro Sanitário. Disponível em: <http://www.cetesb.sp.gov.br/mudancasclimaticas/biogas/Aterro Sanitário/21-Aterro Sanitário>. Acesso em: 04 maio 2015.

CETESB. Poluentes. Disponível em: <http://www.cetesb.sp.gov.br/ar/Informa??esB?sicas/21-Poluentes>. Acesso em: 20 abr. 2015.

CONAMA. Resolução $\mathbf{N}^{\circ}$ 401, de 4 de Novembro de 2008. Brasília, DF, 5 jan. 2008. p. 108-109. Disponível em: 〈http://www.mma.gov.br/port/conama/legiabre.cfm?codlegi=589>. Acesso em: 25 maio 2015.

CONAMA. Resolução N 430, de 13 de Maio de 2011. Brasília, DF, 16 jan. 2011. p. 89-89. Disponível em: <http://www.mma.gov.br/port/conama/res/res11/res43011.pdf>. Acesso em: 28 maio 2015.

CORREIA, F. V.; MERCANTE, F. M.; FABRÍCIO, A. C.; DE CAMPOS, T. M. P.; VARGAS JUNIOR.; LANGENBACH, T. Adsorção de atrazina em solo tropical sob plantio direto e convencional. Pesticidas: Pesticidas: Revista de Ecotoxicologia e Meio Ambiente, Curitiba, v. 17, n. 1, p.37-46, 2008. DOI: 10.5380/pes.v17i0.10663. Disponível em: <http://ojs.c3sl.ufpr.br/ojs/index.php/pesticidas/article/view/10663>. Acesso em: 28 maio 2015.

DANTAS, I. M.; FERREIRA-JUNIOR, W. A.. Análise do aterro sanitário de Quirinópolis/GO segundo as leis ambientais.Anais da Conferência Internacional de Estratégia em Gestão, Educação e Sistemas de Informação (CIEGESI), Anápolis, v. 1, n. 1, p.124-143, 2012. Disponível em: <http://www.anais.ueg.br/index.php/ciegesi/article/view/766>. Acesso em: 27 maio 2015.

ELLIS, J. B.. PollutionalAspectsofUrbanRunoff. In: TORNO, H. C.; MARSALEK, J.; DESBORDES, M. (Ed.). Urban Runoff Pollution. Berlim: Springer Berlin Heidelberg, 1986. p. 1-38.

FACED/UFBA. Metareciclagem: Uma Idéia Inteligente. Disponível em: <https://twiki.ufba.br/twiki/bin/view/MetaReciclagem/Vejamais>. Acesso em: 04 maio 2015.

FERREIRA, J. M. B.; FERREIRA, A. C.. A sociedade da informação e o desafio da sucata eletrônica. Revista de Ciências Exatas e Tecnologia, Valinhos, v. 3, n. 3, p.157-170, 2008. Disponível em: <http://sare.anhanguera.com/index.php/rcext/article/viewArticle/417>. Acesso em: 27 maio 2015.

FIFA. Estádios de Futebol: Recomendações e requisitos técnicos. 5. ed. Brasil: Fifa, 2011. 435 p. Disponível em: <http://img.fifa.com/mm/document/tournament/competition/01/37/17/76/p_sb2010_stadiumb ook ganz.pdf $>$. Acesso em: 28 maio 2015.

FURTADO, J. S.. Baterias esgotadas: legislações \& modelos de gestão. São Paulo: Ministério do Meio Ambiente, 2004. 95 p. Disponível em: 
<http://www.mma.gov.br/port/conama/processos/0330EB12/BateriasEsgotadasLegislacaoGes tao.pdf $>$. Acesso em: 28 maio 2015.

GONÇALVES, V. F.; BRUNO, C. G. C.; SOUZA, C. R.; FAÇANHA, P. E. W.; ALVES, M. C.; BORGES, M. P.; MELO, C.. Utilização de liquens como bioindicadores da qualidade atmosférica na cidade de Uberlândia, MG. In: VIII CONGRESSO DE ECOLOGIA DO BRASIL, 8., 2007, Caxambu. Anais do VIII Congresso de Ecologia do Brasil. Caxambu: Sociedade de Ecologia do Brasil, 2007. Disponível em: <http://sebecologia.org.br/viiiceb/pdf/1185.pdf>. Acesso em: 26 maio 2015.

GOUVEIA, N. ; MENDONÇA, G. A. S.; LEON, A. P. ; CORREIA, J. E. M.; JUNGER, W. L.; FREITAS, C. U.; DAUMAS, R. P.; MARTINS, L. C.; GIUSSEPE, L ; CONCEIÇÃO, G. M. S.; MANERICH, A.; CUNHA-CRUZ, J.. Poluição do ar e efeitos na saúde nas populações de duas grandes metrópoles brasileiras. Epidemiologia e Serviços de Saúde, Brasília, v. 12, n. 1, p.29-40, mar. 2003. DOI: 10.5123/s1679-49742003000100004. Disponível em: < http://scielo.iec.pa.gov.br/scielo.php?pid=S1679-49742003000100004\&script=sci_arttext $>$.

Acesso em: 25 maio 2015.

ICB-UFMG. Bioindicadores. Disponível

em: < http://labs.icb.ufmg.br/benthos/index arquivos/Page1631.htm>. Acesso em: 28 maio 2015.

KASPER, A. C.; COSTA, R. C.; ANDRADE, P. A.; VEIT, H. M.; BERNARDES, A. M. Caracterização de Sucatas Eletrônicas Provenientes de Baterias Recarregáveis de Íons de Lítio, Telef. Revista Brasileira de Ciências Ambientais, Porto Alegre, v. , n. 12, p.9-17, abr. 2009. Disponível em: <http://www.rbciamb.com.br/images/online/RBCIAMB-N12-Abr2009-Materia02_artigos201.pdf>. Acesso em: 25 maio 2015.

LIMA, G. F. C.. Questão ambiental e educação: contribuições para o debate. Ambiente \& Sociedade, Campinas, n. 5, p.135-153, 1999. DOI: 10.1590/s1414-753x1999000200010. Disponível em: $\quad$ http://www.scielo.br/scielo.php?pid=S1414753X1999000200010\&script=sci_arttext $>$. Acesso em: 25 maio 2015.

MANO, E. B.; PACHECO, B. A. V.; BONELli, C. M. C.. Meio Ambiente, Poluição e Reciclagem. São Paulo: Blucher, 2005. 200 p.

NASCIMENTO, N. O.; HELLER, L.. Ciência, tecnologia e inovação na interface entre as áreas de recursos hídricos e saneamento. Engenharia Sanitaria e Ambiental, Rio de Janeiro, v. 10, n. 1, p.36-48, 2005. DOI: 10.1590/s1413-41522005000100005. Disponível em: $<$ http://www.scielo.br/readcube/epdf.php?doi=10.1590/S1413-

41522005000100005\&pid=S1413-415220050001000>. Acesso em: 27 maio 2015.

NÓBREGA, M. R. R.; KOHN, L. G. ${ }^{1}$; MILANI, I. C. B. ; NEBEL, A. L. C. ; TAVARES, V. E. Q. ; SUZUKI, L. E. A. S. ; COLLARES, G. L.. Caracterização do Chorume de um Aterro Controlado em Pelotas/RS. In: IX MOSTRA ENPOS - I MOSTRA CIENTÍFICA, 18., 2009, Pelotas. XVIII Congresso de Iniciação Científica da UFPel. Pelotas: Engenharia 
<http://wp.ufpel.edu.br/rhima/files/2010/09/CE_01502.pdf>. Acesso em: 28 maio 2015.

PALMA-FILHO, J. C.. Parâmetros Curriculares Nacionais. Nuances: Estudos Sobre Educação, Presidente Prudente, v. 3, n. 3, p.15-19, set. 1997. Disponível em: <http://revista.fct.unesp.br/index.php/Nuances/article/view/51>. Acesso em: 25 maio 2015.

PRODANOFF, J. H. A.. Avaliação da Poluição Difusa Gerada por Enxurradas em Meio Urbano. 2005. 276 f. Tese (Doutorado) - Curso de Pós-graduação em Engenharia Civil, Universidade Federal do Rio de Janeiro, Rio de Janeiro, 2005. Disponível em: <http://www.coc.ufrj.br/index.php/teses-de-doutorado/149-2005/1030-jorge-henrique-alvesprodanoff>. Acesso em: 28 maio 2015.

RIBEIRO, B. A. L.; CAMELlo, T. C. F.. Reflexões Sobre o Uso de Agrotóxicos e Suas Consequências. Revista Sustinere, Rio de Janeiro, v. 2, n. 2, p.27-35, 2014. DOI: 10.12957/sustinere.2014.14125. Disponível em: <http://www.epublicacoes.uerj.br/index.php/sustinere/article/view/14125>. Acesso em: 25 maio 2014.

RIBEIRO, H.; BESEN, G. E.. Panorama da Coleta Seletiva no Brasil: Desafios e Perspectivas a Partir de Três Estudos de Caso. InterfacEHS - Revista de Gestão Integrada em Saúde do Trabalho e Meio Ambiente, São Paulo, v. 2, n. 4, p.1-18, ago. 2007. Disponível em: <http://www.revistas.sp.senac.br/index.php/ITF/article/viewFile/138/166>. Acesso em: 27 maio 2015.

RICARDO, E. C.; ZYLBERSZTAJN, A.. Os Parâmetros Curriculares Nacionais na Formação Inicial dos Professores das Ciências da Natureza e Matemática do Ensino Médio. Investigações em Ensino de Ciências, Porto Alegre, v. 12, n. 3, p.339-355, dez. 2007. Disponível em: <http://www.if.ufrgs.br/ienci/main/artigos/openAbstract.php?idArtigo=175>. Acesso em: 25 maio 2015.

RODRIGUES, M. I.; MOLINA, A. A.. Conselho Escolar: Uma proposta de gestão para envolver a participação comunitária de maneira mais atuante, consciente e crítica na escola. $\mathbf{O}$ Professor PDE e Os Desafios da Escola Pública Paranaense, Paraná, 2012.

SILVA, F. L.; RODRIGUES, P. F. M.; TALAMONI, J. L. B.; RUIZ, S. S.; ANDREO, M.; BUENO, S. F.; BOCHINI, G. L..Bioindicadores da qualidade da água: subsídios para um projeto de educação ambiental no Jardim Botânico Municipal de Bauru, SP. Revista Ciência em Extensão, São Paulo, v. 5, n. 1, p.94-105, 2009. Disponível em: <http://ojs.unesp.br/index.php/revista_proex/article/view/14>. Acesso em: 28 maio 2015.

SILVA, J. A. B.. Urbanização no mundo contemporâneo e os problemas ambientais. Cadernos de Graduação, Ciências Humanas e Sociais, Aracaju, v. 2, n. 2, p.197-207, 2014. Disponível em: <https://periodicos.set.edu.br/index.php/cadernohumanas/article/view/1723>. Acesso em: 27 maio 2015. 
SOARES, A. C. C.. Estudo Retrospectivo de Queixas Músculos-esqueléticas em Trabalhadores de Frigorífico. 2004. 85 f. Dissertação (Mestrado) - Curso de Pós-graduação em Engenharia de Produção, Departamento de Engenharia de Produção e Sistemas, Universidade Federal de Santa Catarina, Santa Catarina, 2004. Disponível em: <https://repositorio.ufsc.br/xmlui/handle/123456789/86820 >. Acesso em: 28 abr. 2015.

VALLE, C. E.. Qualidade Ambiental ISO 14000. São Paulo: Senac, 2012. 208 p.

VORMITTAG, E. M. P. A. A.; COSTA, R.R.; BRAGA, A. A.; MIRANDA, M.; NASCIMENTO, N. C.; SALDIVA, P. H. N.. Monitoramento da qualidade do ar no Brasil. São Paulo: Conama/ministério do Meio Ambiente (MMA), 2014. 16 p. Disponível em:

$<$ http://www.mma.gov.br/port/conama/processos/C1CB3034/Monitoramento Qualidade Ar Brasil1.pdf $>$. Acesso em: 28 maio 2015.

WINK, C.; GUEDES, J. V. C. ; FAGUNDES, C. K.; ROVEDDER, A. P..Insetos edáficos como indicadores da qualidade ambiental. Revista de Ciências Agroveterinárias, Lages, v. 4, n. 1, p.60-71, 2006. Disponível em: 〈http://rca.cav.udesc.br/rca_2005_1/wink.pdf〉. Acesso em: 27 maio 2015. 